\title{
First record of Plectris aliena Chapin, 1934 (Coleoptera: Melolonthidae) as a potential
}

\section{sugarcane pest in Brazil}

Gilmar Vieira Coutinho ${ }^{1} \odot$, Elias Soares Gomes ${ }^{2} \oplus$, Crébio José Ávila ${ }^{3 \oplus}$, Ivana Fernandes da Silva ${ }^{2 *} \oplus$, Eduardo Neves Costa ${ }^{4}$, Mariana Alejandra Cherman ${ }^{5}$

'Legado Pesquisa e Consultoria Agronômica, R. Artur Frantz, 1455 - 79823-290 - Dourados, MS - Brasil.

2Universidade Federal da Grandes Dourados - Depto.

de Entomologia e Conservação da Biodiversidade, Rod. Dourados/tahum, km 12 - 79804-970 - Dourados, MS Brasil.

3Embrapa Agropecuária Oeste, Rod. BR 163, km 253,6 79804-970 - Dourados, MS - Brasil.

${ }^{4}$ Universidade Federal da Grandes Dourados - Depto. de Agronomia, Rod. Dourados/Itahum, km 12 - $79804-970$ Dourados, MS - Brasil.

${ }^{5}$ Universidade Federal do Mato Grosso - Depto. de Biologia e Zoologia, Av. Fernando Corrêa da Costa, 2367 - 78060900 - Cuiabá, MG - Brasil.

*Corresponding author <ivanaf.silva@hotmail.com>

Edited by: Alberto Soares Corrêa

Received May 05, 2020

Accepted December 15, 2020
ABSTRACT: Plectris aliena Chapin, 1934, a white grub that promotes serious damage to a variety of crops in North America and Australia, has been reported for the first time in Brazil. Larvae and adults of $P$. aliena were recorded in sugarcane crops in the state of Mato Grosso do Sul, sampled by trenches in the soil with light traps, respectively, during 2012 and 2013. Root consumption was also determined for the first, second and third instar larvae. The species is univoltine; adults were found mainly in Aug and the peak of third instar larval density was in Apr in all fields sampled. Pupae and adults of $P$. aliena were observed in the soil profile at depths of up to 60 and $80 \mathrm{~cm}$, respectively. Larvae of $P$. aliena of the second and third instar consumed the primary and secondary roots of sugarcane, causing serious damage. Third instar larvae consumed $916 \mathrm{mg}$ of root fresh matter, representing $72 \%$ of the sugarcane root system. These results assist in furthering the understanding of its larval dynamics in the soil and provide support for Integrated Pest Management.

Keywords: Macrodactylini, Scarab beetles, root-feeding pests, temporal distribution, white grubs

\section{Introduction}

Plectris LePeletier and Audinet-Serville, 1828 is one of the richest genus within Macrodactylini, with 358 species distributed in the Neotropical region (Evans and Smith, 2009; Krajčik, 2012). This genus can be found in Guatemala, Nicaragua and the Lesser Antilles (Saint Vincent and Martinique) through all the South American countries except Suriname, and it is concentrated in abundance mainly in Brazil (227 species) and Argentina (28 species) (Frey, 1967; Evans and Smith, 2009). Plectris aliena Chapin, 1934, is the only species recorded outside the Neotropical region, and has been described from specimens collected in Charleston, South Carolina, USA (Chapin, 1934). The current records of this species are from the southeastern states of the USA, Queensland and New South Wales (Australia) (Brill and Abney, 2013; Allsopp and Hutchinson, 2018).

The life cycle of $P$. aliena could last up to one year in South and North Carolina (Chapin, 1934; Brill and Abney, 2013) or two years in New South Wales (Australia) (Roberts, 1968), and females showed preference for the type of soil for laying eggs, mostly in a sandy loam texture and poorly drained soils (Roberts, 1968; Brill et al., 2013; 2016). Larvae were recorded causing damage mainly in pastures as well as in soybean (Glycine max (L.) Merrill Fabaceae), maize (Zea mays L. Poaceae), cotton (Gossypium hirsutum L. Malvaceae), peanut (Arachis hypogaea L. Fabaceae) and tobacco (Nicotiana tabacum L. Solanaceae) crops (Brill et al., 2013). In North Carolina, USA, $P$. aliena has caused more than US\$ 16 million losses to sweet potato growers, Ipomoea batatas (L.) Lam. (Convolvulaceae). In the case of this crop, larvae render the tubers unmarketable regardless of the severity of damage (Brill et al., 2013). Jackson et al. (2010) reported damage of $28 \%$ in sweet potato tubers caused by larvae of $P$. aliena, while according to Schalk et al. (1992; 1993) damage reached $37 \%$. The unique record of $P$. aliena in sugarcane, Saccharum officinarum L. (Poaceae) has been reported by Samson et al. (2013) in New South Wales (Australia).

Herein, we report, for the first time, on the occurrence of $P$. aliena in South America associated with sugarcane crops in Mato Grosso do Sul, Brazil. We also provide information on its life cycle both in the laboratory and in the field and warns about its potential as a sugarcane pest.

\section{Materials and Methods}

\section{Collection location}

This study was conducted in sugarcane growing areas in Mato Grosso do Sul, in the municipality of Nova Andradina $\left(21^{\circ} 58^{\prime} \mathrm{S}\right.$ and $53^{\circ} 25^{\prime} \mathrm{W}$, altitude of $\left.380 \mathrm{~m}\right)$. A total of 24 plots were sampled with sizes ranging 
from 20 to 50 hectares. The weather in this region is classified as Aw according to the Köppen's classification, corresponding to a hot-humid tropical environment, with rainy summers and dry winters (Alvares et al., 2013). The annual mean temperature of Nova Andradina is $22.7^{\circ} \mathrm{C}$, with a mean rainfall of $1369 \mathrm{~mm}$ (IBGE, 2019).

\section{Seasonal distribution of Plectris aliena in sugarcane}

From May 2012 to Apr 2013, we sampled the soil and used light traps to obtain $P$. aliena immatures and adults, respectively. For larval sampling, trenches $30 \times 30 \times$ $30 \mathrm{~cm}$ (length $\times$ width $\times$ depth) were opened in the sugarcane (variety RB935744) rows. A total of 480 trenches were opened during one year $(n=20$ trenches every 15 days). In addition, larger trenches $50 \times 80 \times$ $40 \mathrm{~cm}$ were dug, making a total of 96 trenches in order to obtain data on the vertical distribution of immatures, and to check for possible insect migration in the soil profile. Each large trench was subdivided into four layers $10 \mathrm{~cm}$ deep $(0-10,10-20,20-30$ and 30-40 cm) and five segments $10 \mathrm{~cm}$ wide from the planting row (0-30 $\mathrm{cm})$ to the adjacent stratum of $30-40,40-50,50-60,60-$ $70,70-80 \mathrm{~cm}$, to obtain horizontal distribution data. The percentage of $P$. aliena larvae present was calculated for each depth and horizontal layer.

The "Luiz de Queiróz" light trap model equipped with a 20-watt fluorescent lamp, was used from 6 p.m. to 6 a.m., to collect adult P. aliena. A light trap was also used for each collection event, taking 24 samplings over the period of one year.

\section{Sample transport and identification}

Immature and adult $P$. aliena were individualized in 500 $\mathrm{ml}$ plastic containers with soil and sugarcane fragments and transported to the municipality of Dourados, Mato Grosso do Sul, Brazil, $\left(22^{\circ} 16^{\prime}\right.$ S e $54^{\circ} 49^{\prime} \mathrm{W}$, altitude of $408 \mathrm{~m})$.

Adults were identified from the entomological key to Plectris species (Frey, 1967), and confirmed by comparison with the primary type housed at the entomological collection in the Smithsonian Institute (USNM, Curator Manager Floyd Shokley). Larvae were identified using the key to Melolontidae larvae of Cherman et al. (2013) and compared with the description of Böving (1936). Voucher specimens were deposited in the "Padre Jesus Santiago Moure" Collection (DZUP), Curitiba, Brazil.

\section{Biology of Plectris aliena in the laboratory}

The larvae of $P$. aliena $(\mathrm{n}=150)$ were reared in 500 $\mathrm{mL}$ plastic containers with sugarcane seedlings in the soil. The soil was moistened weekly, and the seedlings replaced every 15 days so as to provide new roots as food for the larvae. The plastic containers were checked at intervals of 5-7 days, carefully removing the soil and seedlings to have sight of the larvae. After reaching the pre-pupa stage, the insects become white, opaque and ceased feeding. At this stage the supply of sugarcane seedlings was discontinued. Periodically, the pupal chambers had to be opened to evaluate the pupal duration.

After emerging, adults were sexed according to the length of the lamellae (Brill and Abney, 2013), then grouped in pairs and housed in $1000 \mathrm{~mL}$ transparent cages containing a soil layer at a depth of $10 \mathrm{~cm}$ obtained from the collection site and sugarcane seedlings to facilitate mating and ovipositing activities. The plastic cages were covered with polyester fabric and checked daily for egg laying. The eggs were collected and maintained in Petri dishes (10 cm diameter) lined with $2-3 \mathrm{~cm}$ of sieved and moistened soil which were stored in a chamber with control of photoperiod and temperature $\left(26 \pm 2{ }^{\circ} \mathrm{C}\right.$ and $\mathrm{L}$ : D 12:12 h). The containers used for rearing larvae and adults were kept at ambient temperature.

A digital paquimeter (accuracy of $0.05 \mathrm{~mm}$ ) was used to monitor larval growth and differentiation of instars by measuring the cephalic capsule at its maximum width obtained at intervals of 5-7 days. The length and width of eggs, larvae and pupae were obtained using the same tool, whereas their weight was evaluated with an analytical precision scale (accuracy of $0.0001 \mathrm{~g}$ ). The life cycle of $P$. aliena was determined by examining the duration of its different developmental stages.

\section{Sugarcane root consumption by Plectris aliena}

The consumption of sugarcane root was determined for first-, second-, and third-instar larvae of $P$. aliena. For first-instar larvae, the evaluation was performed qualitatively, through observation of sugarcane seedlings after 10 days of larval consumption. To carry this out, a total of 10 larvae (7-days old) were released in one $500 \mathrm{~mL}$ container containing sugarcane seedlings and soil using five replicates. The consumption of sugarcane root by second and third-instar larvae was determined quantitatively and consisted of three treatments: 1) second-instar larvae, 2) third-instar larvae, and 3) control (no infestation).

This study was conducted using a completely randomized design with 10 replicates for each treatment. The experimental unit consisted of one container with a sugarcane seedling and one larva. Seedlings were selected at random and the period of evaluation of consumption lasted six days. At the end of this period, the fresh and dry matter of the remaining roots in the different treatments was quantified.

\section{Statistical analysis}

Data were subjected to analysis of variance, and when a significant effect of the treatment was observed, the means were compared by Tukey's test to $5 \%$ of probability. The analyses were performed using the SAS 
statistical program (Statistical Analysis System, v. 9.1), and the normality of the data assessed by the Cochran test. Linear regression equations were adjusted for data referring to horizontal and vertical distribution for larval numbers present in the soil profile.

\section{Results}

The presence of Plectris aliena (Figure 1A-E) was recorded in all 24 sugarcane plots where immatures were sampled. All stages of insect development were observed throughout the sampling period (Figure 2). From the soil trenches 2,566 larvae, seven pupae and 62 adults of $P$. aliena were collected. In contrast, a total of
A
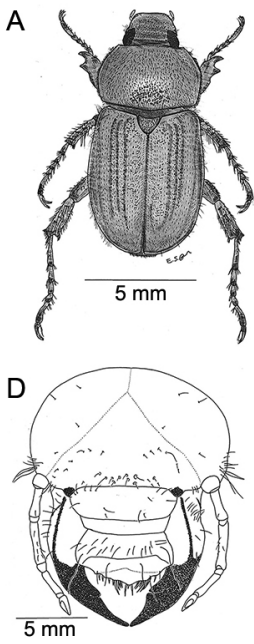
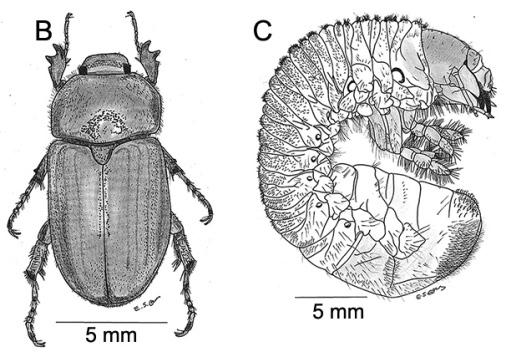

$\mathrm{E}$

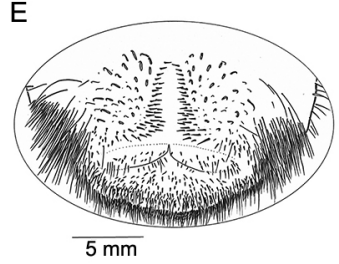

Figure 1 - Plectris aliena Chapin, 1934. Morphology in adults. Male habitus (A) and female (B); Morphology of larvae. Body in lateral view (C); head in frontal view (D) and raster (E). Credit: Elias Soares Gomes. seven adults, including both sexes were captured in the light trap. Adults on the soil were observed from July to Sept, followed by the larval period which started in Sept, with peaks of population density of the third-instar from Feb to Apr, while the pupal period was ascertained to be May to Sept (Figure 2).

The larval movement in the soil profile, as well as the gradual increase of the larval density after the reproductive period, explains the univoltine life cycle of this species (Figure 2 and 3). The low or zero larval population density recorded from Aug to Oct (Figure 3) was obtained from the trenches dug to a depth of 30 $\mathrm{cm}$. During the subsequent months, the larval density increased gradually until Apr, when the peak of larvae occurred (155 larvae $\mathrm{m}^{2}$ ). In May, the density of the third-instar larvae decreased, which matches with the increase of pupae in the soil profile, whose presence was confirmed only at depths greater than $30 \mathrm{~cm}$. Upon reaching the pre-pupal stage, the insects build their pupal chambers for shelter and protection. The pupae were found at the 30,40, and $60 \mathrm{~cm}$ depths, whereas the presence of adults was detected at depths down to $80 \mathrm{~cm}$.

Plectris aliena eggs were found in the soil down to the $40 \mathrm{~cm}$ depth and first-instar larvae were observed from the end of Aug (Figure 2). These larvae were concentrated right below the planting row of sugarcane, down to $40 \mathrm{~cm}\left(\mathrm{y}=-1.1448 \mathrm{x}+53.619, \mathrm{r}^{2}=0.95, \mathrm{~F}=\right.$ $42.14, p=0.02, \mathrm{SE}=0.18$ ) (Figure 4). With regard to the horizontal distribution, although larvae were found in all horizontal distances sampled, the greatest concentration was found at the planting row $(0$ to $30 \mathrm{~cm})(66.3 \%)$ (y $=279.58 \mathrm{e}^{-0.064 \mathrm{x}}, \mathrm{r}^{2}=0.93, \mathrm{~F}=5.95, p=0.07, \mathrm{SE}=$ 0.42) (Figure 5). This may be related to the availability of food and shelter of this environment, once the larvae population had decreased in line with the distance from the planting row.

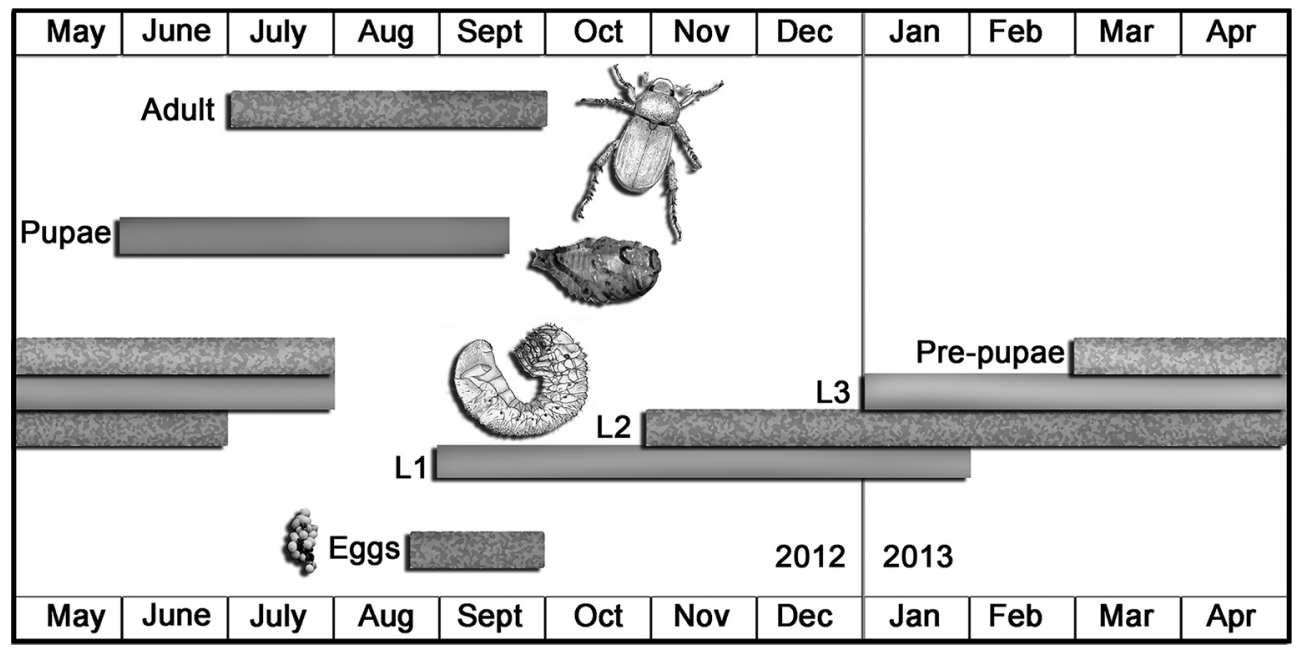

Figure 2 - Life cycle of Plectris aliena in the sugarcane crop, in Nova Andradina, Mato Grosso do Sul, from May 2012 to Apr 2013. Credit: Elias Soares Gomes 
Females of $P$. aliena reared in the laboratory laid 52 eggs on average, distributed over three oviposition periods. In the first and second periods, the egg laying was en masse, consisting of 25 and 15 eggs, respectively. The third egg laying had an average of 12 eggs randomly dispersed in the soil. The eggs were spherical-shaped, measuring from 1.1 to $1.5 \mathrm{~mm}$ diameter with a mean embryonic period of 15 days $(\mathrm{n}=80)$.

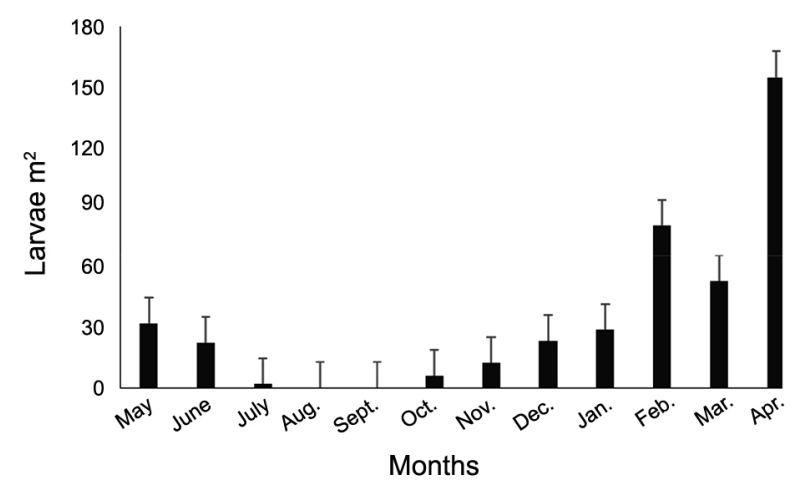

Figure 3 - Monthly mean number of Plectris aliena larvae $\mathrm{m}^{2}$, found up to $30 \mathrm{~cm}$ deep referring to the trenches of $30 \times 30 \times 30$, sampled in the sugarcane crop, Nova Andradina, Mato Grosso do Sul, during the years 2012 and 2013.

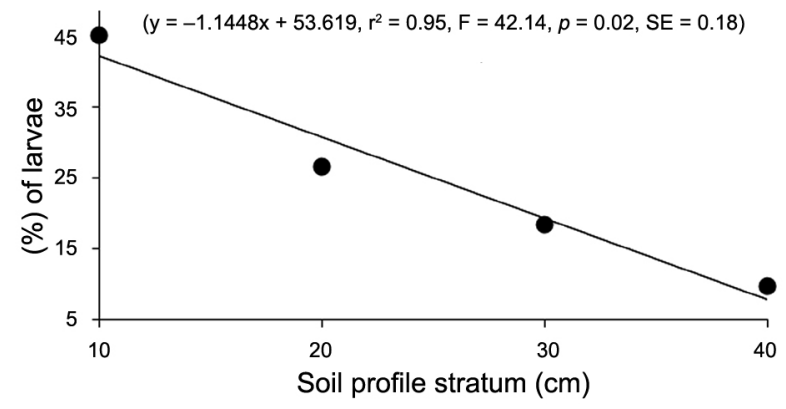

Figure 4 - Vertical distribution of Plectris aliena larvae in the soil profile $(\mathrm{cm})$ in sugarcane crop, Nova Andradina, Mato Grosso do Sul.

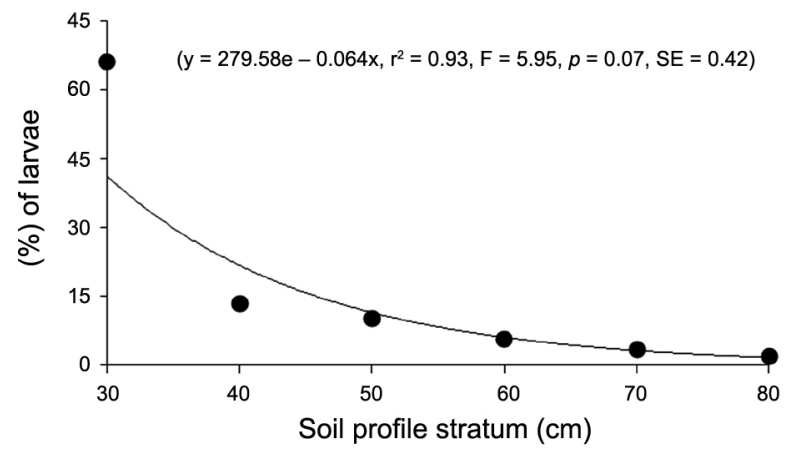

Figure 5 - Horizontal distribution of Plectris aliena larvae in the soil profile (cm) in sugarcane crop, Nova Andradina, Mato Grosso do Sul.
The first-instar larvae were $0.74 \pm 0.33 \mathrm{~cm}$ in length, with a mean cephalic capsule width of $1.47 \pm$ $0.04 \mathrm{~mm}$, and biomass of $94.0 \pm 6.43 \mathrm{mg}$ (Table 1). At the end of the first-instar larvae reached a maximum 1.8 $\mathrm{mm}$ in cephalic capsule width, a period in which ecdysis was observed. Second-instar larvae were $1.87 \pm 0.68 \mathrm{~cm}$ in length and weighed a mean of $219.7 \pm 29.90 \mathrm{mg}$, with a mean cephalic capsule width of $2.86 \pm 0.06 \mathrm{~mm}$, and ecdysis for larvae with a $3.5 \mathrm{~mm}$ cephalic capsule width was observed (Table 1). Third-instar larvae measured 2.49 $\pm 0.47 \mathrm{~cm}$ in length, and $369.6 \pm 23.32 \mathrm{mg}$ in weight, and there was a higher frequency of individuals showing $4 \mathrm{~mm}$ cephalic capsule in width. In the laboratory, the periods of duration of the first, second, and third larval instars were $27.0 \pm 12.50 ; 32.7 \pm 30.42$ and $62.5 \pm 21.36$ days, respectively (Table 1 ).

The pre-pupa lasted, in the laboratory, a mean of $137.9 \pm 17.51$ days. On reaching a body mass of $426.4 \pm$ $23.61 \mathrm{mg}$, the third-instar larvae stop feeding and remain inactive until the pupal phase. After becoming pupae, they experienced a reduction in biomass $1372.6 \pm 22.65$ $\mathrm{mg}$ ) and remained in the interior of the pupal chamber for 18.9 days. In the laboratory, the adults showed a mean longevity of $28.8 \pm 2.00$ days (Table 1 ), with the longest recorded longevity of 42 days.

The first-instar larvae of $P$. aliena fed on younger sugarcane roots, especially on root hairs. This probably caused a reduction in the absorption of water and nutrients by plants, making them yellowish and parched, compared to uninfested plants. The second and thirdinstar larvae consumed the primary and secondary roots, and consequently their attack resulted in more severe damage. However, the greater root fresh matter $(\mathrm{F}=$ 37.65; $g l=27 ; p=0.0229)$ and dry mass $(\mathrm{F}=21.08 ; g l=$ $27 ; p=0.0229$ ) consumption was caused by third-instar larvae that significantly differed from the consumption of second-instar larvae and control (Table 2).

Table 1 - Mean ( \pm SE) of the cephalic capsule width, length, biomass (body mass), and duration of the developmental stages of Plectris aliena in laboratory.

\begin{tabular}{|c|c|c|c|c|}
\hline Period & $\begin{array}{l}\text { Cephalic } \\
\text { Capsule }\end{array}$ & Length & Biomass & Duration \\
\hline & $\mathrm{mm}$ & $\mathrm{cm}$ & $\mathrm{mg}$ & days \\
\hline \multirow[t]{2}{*}{$1^{\circ}$ Instar } & $1.47 \pm 0.04$ & $0.74 \pm 0.33$ & $94.0 \pm 6.43$ & $27.0 \pm 12.50$ \\
\hline & $n=32$ & $n=24$ & $\mathrm{n}=9$ & $n=6$ \\
\hline \multirow[t]{2}{*}{$2^{\circ}$ Instar } & $2.86 \pm 0.06$ & $1.87 \pm 0.68$ & $219.7 \pm 29.90$ & $32.7 \pm 30.42$ \\
\hline & $n=58$ & $n=40$ & $n=6$ & $n=3$ \\
\hline \multirow[t]{2}{*}{$3^{\circ}$ Instar } & $4.00 \pm 0.03$ & $2.49 \pm 0.47$ & $369.6 \pm 23.32$ & $62.5 \pm 21.36$ \\
\hline & $\mathrm{n}=80$ & $n=33$ & $\mathrm{n}=10$ & $n=6$ \\
\hline \multirow[t]{2}{*}{ Pre-pupae } & - & - & $426.4 \pm 23.61$ & $137.9 \pm 17.51$ \\
\hline & & & $\mathrm{n}=11$ & $\mathrm{n}=10$ \\
\hline \multirow[t]{2}{*}{ Pupae } & - & - & $372.6 \pm 22.65$ & $18.9 \pm 1.00$ \\
\hline & & & $\mathrm{n}=3$ & $n=24$ \\
\hline \multirow[t]{2}{*}{ Adult } & - & - & - & $28.8 \pm 2.00$ \\
\hline & & & & $\mathrm{n}=22$ \\
\hline Total & & & & 307.80 \\
\hline
\end{tabular}

$\mathrm{SE}=$ Standard error; $\mathrm{n}=$ number of insects assessed. 
Considering the differences between the control (uninfested plants) and the treatments with infestation of second or third instar larvae, we calculated the average amount of roots consumed during the six days of feeding. The second instar larvae consumed, on average, $0.685 \mathrm{~g}$ of fresh root, while the third instar larvae consumed, on average, $0.916 \mathrm{~g}$ of fresh root (Table 2), representing approximately 54 and $72 \%$, respectively, of the fresh matter of the root system of sugarcane seedlings with no damage.

\section{Discussion}

The biological cycle of $P$. aliena in the sugarcane fields in Mato Grosso do Sul (Brazil) is univoltine. This matches with the cycle observed by Chapin (1934) and Brill and Abney (2013) in the southeastern states of the USA, although different to what had been pointed out by Samson et al. (2013) in sugarcane in Australia.

Adults of $P$. aliena collected during July and Sept in the present study, which corresponds to winter in the southern hemisphere. In North Carolina (USA), Brill and Abney (2013) observed that adults emerge, mate and lay eggs from May to June, which corresponds to summer in the northern hemisphere instead. There are few records in the literature on other Plectris. In the region of the Vale de Cauca, Colombia, adults of Plectris fassli Moser, 1919 and Plectris pavida Burmeister, 1855 are attracted by light traps between Oct and Nov and during the rainy season of Mar-Apr (Pardo-Locarno et al., 2005). It may indicate that the periods when adults emerge are quite different among the Plectris species.

Pardo-Locarno et al. (2005) reported a population density of $P$. fassali of up to 40 larvae $\mathrm{m}^{2}$ in pasture and 34 larvae $\mathrm{m}^{2}$ in cassava (Manihot esculenta) crops. These authors also found that $P$. pavida prospered in abundance in pasture areas, reaching a density of up to 21 larvae $\mathrm{m}^{2}$. It is possible that the larval density is influenced by the type of crop, soil and climate. In a study on sugarcane crops in Somalia, Cock and Allard (2013) reported third instar larvae of Cochliotis melolonthoides

Table 2 - Mean ( \pm SE) of the fresh mass (FM), fresh mass consumed (FMC), dry mass (DM) and dry mass consumed (DMC) considering the remaining sugarcane seedling roots, after six days of feeding of different larval stages of Plectris aliena.

\begin{tabular}{lcccc}
\hline Larval instar & FM & FMC & DM & DMC \\
\cline { 2 - 5 } Control & $1.274 \pm 0.101 \mathrm{a}$ & - & $0.290 \pm 0.037 \mathrm{a}$ & - \\
& $\mathrm{n}=10$ & & $\mathrm{n}=10$ & \\
\hline Third instar & $0.358 \pm 0.027 \mathrm{~b}$ & 0.916 & $0.084 \pm 0.005 \mathrm{~b}$ & 0.206 \\
& $\mathrm{n}=10$ & & $\mathrm{n}=10$ & \\
\hline Second instar & $0.589 \pm 0.084 \mathrm{~b}$ & 0.685 & $0.136 \pm 0.016 \mathrm{~b}$ & 0.154 \\
& $\mathrm{n}=10$ & & $\mathrm{n}=10$ & \\
\hline
\end{tabular}

Means $( \pm$ SE) followed by different letters within columns are significantly different by Tukey's test $(p<0.05)$. SE $=$ Standard error; $n=$ number of insects assessed.
(Gerstaecker, 1867) at a depth of $84 \mathrm{~cm}$ depth and pupae at $61 \mathrm{~cm}$, which is similar to our results. On the other hand, in pastures in the Vale de Cauca (Colombia), $P$. fassali pupae have been recorded at a depth of $35-40 \mathrm{~cm}$ (Pardo-Locarno et al., 2005).

Females of Phyllophaga cuyabana Moser, 1918 (Melolonthinae: Melolonthini) lay eggs in the superficial layer $(3$ to $10 \mathrm{~cm})$; however, their first-instar larvae can be found at the $30 \mathrm{~cm}$ depth level. Second and thirdinstar larvae of this species tend to concentrate in soil between the 5 to $10 \mathrm{~cm}$ soil depth, although they may explore different soil depths. In a soil profile study of Plectris spp., Pardo-Locarno et al. (2005) observed in Nov second-instar larvae in shallow layers, close to the soil surface $(0$ to $10 \mathrm{~cm})$. These larvae remained close to the plant base until reaching the third-instar in Jan. Moreover, these authors showed that Plectris spp. females may lay eggs in the same or a different area from the one used in the previous year. In this study we observed that $P$. aliena presented a form of unusual oviposition, when compared to with other Melolonthinae studied, because they lay eggs in an aggregated manner and at greater depths.

In the current study, $P$. aliena oviposition was found in the form of egg masses, and the pupal chambers were thin-walled and little resistant. During these phases, insects were observed at greater depths, probably in search of shelter and proper conditions for development. The mean of eggs found in this study was greater than that found by Rodrigues et al. (2008) for Liogenys fusca Blanchard 1851 (Melolonthinae: Diplotaxini), which showed a mean of 8.3 eggs, with similar dimensions (1.5 mm diameter) and a 14.3-day embryonic period. A similar result was observed by Oliveira et al. (1996), who reported a low reproductive capability of $P$. cuyabana in the laboratory, with a mean of 17.6 eggs/female and a 13.8 day embryonic period, similar to that of $L$. fusca and P. aliena. The duration of the larval instars of $P$. aliena is similar to those found by Oliveira et al. (1996) for P. cuyabana, in which the duration of the first, second and third larval instars were 26.9, 34.4 and 80.8 days, respectively. Rodrigues et al. (2008) observed that, when starting the pre-pupal period, the larvae of $L$. fusca are whitish in color, and last 120.2 days on average, similar to that observed for $P$. aliena in this research. These authors also reported that the pupal phase has a mean duration of 27.5 days. In general, these results show that these species, even from different tribes and genera, are very similar in terms of duration of development stages.

Our results of root consumption support the previous findings of different authors who have reported $P$. aliena as a crop pest. Chapin (1934) recorded serious damage to the golf courses in Brunswick, Georgia (USA), caused by P. aliena larvae, while Roberts (1968) reported damage in pastures of sandy and deep areas in northeastern New South Wales (Australia), with a mean density of 5 larvae $\mathrm{m}^{2}$. Samson et al. (2013) registered 
P. aliena as a pest also in New South Wales (Australia) for the first time in sugarcane crop. Cuthbert and Reid (1965) made the first report on $P$. aliena damage in sweet potato in Charleston, South Carolina, USA. Jackson et al. (2010) also reported 3 to $28 \%$ damage by $P$. aliena to sweet potato roots. Schalk et al. (1993) observed variations between 0.1 and $37 \%$ of the damage to the roots of sweet potato.

According to Brill and Abney (2013), although $P$. aliena has become an economic problem in North Carolina, its presence in the southern United States and recent expansion to the planting of sweet potato make this insect species a potential threat in most producer states. These authors affirmed that $P$. aliena larvae are capable of surviving and completing their development on several cultivated plant species other than sweet potato, such as soybean, maize, peanut, and tobacco. Brill and Abney (2013) also listed a wide range of plants damaged by $P$. aliena larvae, such as maize, wheat, and soybean. As regards the sugarcane pests belonging to Melolonthini, Liogenys suturalis (Blanchard, 1851) was an important maize pest, considered the most abundant species in Mato Grosso do Sul, where larvae of this species were found during the whole sampling period (Santos and Ávila, 2009).

Although it was not possible to assess the damage caused by $P$. aliena in the field, based on the consumption of roots of this species in the laboratory it can be considered a potential soil pest in sugarcane, representing an economic threat in cultivated areas. This is an important issue for future research, thus serving as support for integrated pest management (IPM). Despite these promising results, there is a need for further research to investigate the life cycle and fertility of $P$. aliena. This may help to understand its biotic potential and the risk that this insect presents not only for sugarcane, but also for other crops. The results obtained in this research are significant in at least two major respects: contribution to the biology of a species of Plectris in Brazil, and the provision of accurate data on the distribution of $P$. aliena, hitherto unknown in South America.

\section{Acknowledgments}

We thank the agency, the oordination for the Coordenação de Aperfeiçoamento de Pessoal de Nivel Superior (Capes) for granting a $\mathrm{PhD}$ Scholarship to the first author. We also thank the anonymous reviewers and the academic editor for all efforts to improve the manuscript. We thank $\mathrm{CNPq}$ - the Brazilian National Council for Scientific and Technological Development - process N (151425/2019-1).

\section{Authors' Contributions}

Conceptualization: Coutinho, G.V.; Ávila, C.J.; Gomes, E.S.; Silva, I.F.; Costa, E.N.; Cherman, M.A. Data acquisition: Coutinho, G.V.; Ávila, C.J. Data analysis: Coutinho, G.V.; Ávila, C.J. Design of methodology: Coutinho, G.V.; Ávila, C.J. Software development: Coutinho, G.V.; Ávila, C.J. Writing and editing: Coutinho, G.V.; Ávila, C.J.; Gomes, E.S.; Silva, I.F.; Costa, E.N.; Cherman, M.A.

\section{References}

Allsopp, P.G.; Hutchinson P.M. 2018. The exotic white grub Plectris aliena Chapin (Coleoptera: Scarabaeidae: Melolonthinae) is more widely distributed in Australia than previously thought. Australian Entomologist 45: 1-6.

Alvares, C.A.; Stape, J.L.; Sentelhas, P.C.; Gonçalves, J.L.M.; Sparove, K.G. 2013. Köppen's climate classification map for Brazil. Meteorologische Zeitschrift 22: 711-728.

Böving, A. 1936. Description of the larva of Plectris aliena Chapin and explanation of new terms applied to the epipharynx and raster. Proceedings of the Entomological Society of Washington 38: 169-185.

Brill, L.N.; Brandenburg, R.L.; Abney, M.R. 2016. Effect of soil moisture on Plectris aliena (Coleoptera: Scarabaeidae) oviposition. Florida Entomologist 99: 574-575.

Brill, N.L.; Osborne, J.; Abney, M.R. 2013. A spatial ecology study on the effects of field conditions and crop rotation on the incidence of Plectris aliena Chapin (Coleoptera: Scarabaeidae) grub damage to sweet potato roots. Environmental Entomology 42: 1046-1051.

Brill, L.N.; Abney, M.R. 2013. Plectris aliena (Coleoptera: Scarabaeidae): a new invasive soil pest in North Carolina agroecosystems. Journal of Integrated Pest Management 4: 1-8.

Chapin, E. 1934. An apparently new scarab beetle (Coleoptera) now established at Charleston, South Carolina. Proceedings of the Biological Society of Washington 47: 33-36.

Cherman, M.A.; Guedes, J.V.C.; Morón, M.A.; Dal Prá, E.; Bigolin, M. 2013. White grubs (Coleoptera: Melolonthidae) in the "Planalto Region" Rio Grande do Sul state, Brazil: key for identification, species richness and distribution. Revista Brasileira de Entomologia 57: 271-278.

Cock, M.J.; Allard, G.B. 2013. Observations on White grubs affecting sugarcane at the Juba Sugar Project, south-western Somalia, in the 1980s, and implications for their management. Insects 4: 241-272.

Cuthbert, F.P.; Reid Jr., W.J. 1965. Four little-known pests of sweet potato roots. Journal of Economic Entomology 58: 581-583.

Evans, A.V.; Smith, A.B.T. 2009. An electronic checklist of the new world chafers (Coleoptera: Scarabaeidae: Melolonthinae). Electronically published, Version 3, Ottawa, Canada.

Frey, G. 1967. The genus Plectris (Philochlaenia) (ColeopteraMelolonthinae) in entomological work from the museum G. Frey Tutzingbei München. Munich, Germany (in German, with abstract in English).

Instituto Brasileiro de Geografia e Estatística [IBGE]. 2019. Brazilian Institute of Geography and Statistics = Instituto Brasileiro de Geografia e Estatística. Available at: https:// www.ibge.gov.br/cidades-e-estados/ms/nova-andradina.html [Accessed July 14, 2020] (in Portuguese)

Jackson, D.M.; Bohac, J.R.; Thies, J.A.; Harrison H.F. 2010. 'Charleston Scarlet' sweet potato. HortScience 45: 306-309. 
Krajčik, M. 2012. Checklist of the world Scarabaeoidea. Animma.X:1-278.

Oliveira, L.J.; Santos, B.; Parra, J.R.P.; Amaral, L.B.; Magri, D.C. 1996. Biological cycle of Phyllophaga cuyabana (Moser) (Scarabaeidae: Melolonthinae (Scarabaeidae: Melolonthinae). Anais da Sociedade Entomoloìgica do Brasil 25: 433-439 (in Portuguese, with abstract in English).

Pardo-Locarno, L.C.; Montoya-Lerma, J.; Bellotti, A.C.; Schoonhoven, A.V. 2005. Structure and composition of the white grub complex (Coleoptera: Scarabaeidae) in agroecological systems of northern Cauca, Colombia. Florida Entomologist 88: 355-363.

Roberts, R.J. 1968. An introduced pasture beetle, Plectris aliena Chapin (Scarabaeidae: Melolonthinae). Journal of the Australian Entomology Society 7: 15-20.

Rodrigues, S.R.; Barbosa, C.D.L.; Puker, A.; Abot, A.R.; Ide, S. 2008. Occurrence, biology and behavior of Liogenys fuscus Blanchard (Insecta, Coleoptera, Scarabaeidae) in Aquidauana, Mato Grosso do Sul, Brazil. Revista Brasileira de Entomologia 52: 637-640.
Samson, P.; Sallam, N.; Chandler, K. 2013. Pests of Australian Sugarcane: Field Guide. BSES, Indooroopilly, Australia.

Santos, V.; Ávila, C.J. 2009. Biological notes and behavior of Liogenys suturalis blanchard (Coleoptera: Melolonthidae) in Mato Grosso do Sul state, Brazil. Neotropical Entomology 38: 734-740.

Schalk, J.M.; Bohac, J.R.; Dukes, P.D. 1993. Potential of nonchemical control strategies for reduction of soil insect damage in sweet potato. Journal of the American Society of Horticulture Science 118: 605-608.

Schalk, J.M.; Jones, A.; Dukes, P.D. 1992. Responses of soil insects tomixed and contiguous plantings of resistant and susceptible sweet potato cultivars. HortScience 27: 1089-1091. 